\title{
Determination of antioxidant indices in dairy cows during the periparturient period
}

\author{
Karolína Píšt’ková, Josef Illek, Romana Kadek \\ University of Veterinary and Pharmaceutical Sciences Brno, Faculty of Veterinary Medicine, \\ Large Animal Clinical Laboratory, Brno, Czech Republic
}

Received July 13, 2018

Accepted February 12, 2019

\begin{abstract}
The aim of the present study was to evaluate indicators of antioxidant status - glutathione peroxidase (GPx); superoxide dismutase (SOD); total antioxidant status (TAS); vitamins A, E and beta carotene in 10 dairy cows of the Holstein breed from 15-20 days ante partum (a.p.) to 25-30 days post partum (p.p.). Blood samples were collected $5 \times$ during this period: $15-20$ days a.p., 1-3 days a.p., 2-3 days p.p., 10-15 days p.p. and 25-30 days p.p. The mean GPX activity was significantly $(P=0.013)$ lower in the $10-15$ days p.p. compared to $15-20$ days a.p. $(P<0.05)$ and $1-3$ days a.p. $(P<0.01)$. The increase of SOD values was monitored throughout the whole experiment. The mean TAS concentration was significantly $(P<0.01)$ decreased $2-3$ days p.p. compared to 25-30 days p.p. A significantly lower mean concentration of vitamin A was also found $2-3$ days p.p. compared to the concentration $15-20$ days a.p. $(P<0.05)$ and 25-30 days p.p. $(P<0.001)$. A significant $(P<0.001)$ decrease in vitamin $\mathrm{E}$ concentration was recorded in cows $2-3$ days p.p. compared to cows 15-20 days a.p. and 25-30 days p.p. The mean concentration of beta carotene was also decreased immediately after calving. Significant changes in the concentration of antioxidant parameters during the periparturient period indicate the occurrence of oxidative stress in dairy cows which can contribute to increased incidence of metabolic diseases.
\end{abstract}

\section{Oxidative stress, antioxidant status, glutathione peroxidase, superoxide dismutase, vitamins}

Under normal physiological conditions, the production of reactive oxygen species (ROS) and the function of the antioxidant defence system (ADS) are in balance (Miller et al. 1993). The periparturient period, i.e. 3 weeks before to 3 weeks after parturition, is a challenging time for dairy cows when cows are more susceptible to many diseases (Spears and Weiss 2008). Changes in protein and lipid metabolism occur during this period. The energy demand is higher, particularly after parturition, for which reason a negative energy balance (NEB) arises. Energy deficiency causes increased lipid mobilization which leads to lipid peroxidation and further creation of ROS (Sordillo 2005; Sordillo and Aitken 2009; Pilarczyk et al. 2012). A larger amount of ROS causes oxidative stress and may contribute to a higher incidence of diseases after parturition (Miller et al. 1993). Common diseases include liver steatosis and ketosis linked to NEB and a disruption of energy metabolism and mastitis, metritis and retained placenta which are associated with a disturbed immune function (Esposito et al. 2014; Illek 2017). Antioxidants play a key role in immunity and health in transition cows. A deficiency of vitamins (important cellular antioxidants) can cause a weakening of immunity and lead to the above-mentioned diseases (Spears and Weiss 2008). Therefore, the antioxidant levels should be controlled and used for the monitoring of oxidative stress.

The aim of this study was to determine antioxidant indices such as glutathione peroxidase (GPx), superoxide dismutase (SOD), total antioxidant status (TAS), and vitamins $\mathrm{A}, \mathrm{E}$ and beta carotene. The changes in the concentration of the determined indices during the periparturient period were subsequently analysed.

Address for correspondence:

Mgr. Karolína Píšt'ková

Large Animal Clinical Laboratory

Faculty of Veterinary Medicine

University of Veterinary and Pharmaceutical Sciences Brno

Palackého tř. 1946/1, 612 42, Brno, Czech Republic 
Animals and diets

\section{Materials and Methods}

The study was carried out using 10 Holstein dairy cows at a farm located in the village of Uherčice (Břeclav, South Moravia). Blood samples were taken at five different stages: 15-20 days and 1-3 days ante partum (a.p.) and 2-3 days, 10-15 days and 25-30 days post partum (p.p.). Antioxidant indices were determined in a total of 50 blood samples (10 samples/cows for each group). Only cows with a single pregnancy were included in the experiment. All of the cows were fed a total mixed ration (TMR) according to the antepartum and the postpartum period (average body condition score - BCS of 3.6 a.p.) and had gone through two or more lactations (Table 1). The mean milk production was 11,161 litres per last lactation.

Table 1. Total mixed ration composition ( $\mathrm{kg} / \mathrm{day} / \mathrm{cow})$.

\begin{tabular}{lcc}
\hline Ingredients & Ante partum & Post partum \\
\hline Alfalfa hay & 0 & 1 \\
Barley straw & 2.2 & 0 \\
Concentrate (DOVP) & 0 & 5 \\
Concentrate (DOVP - a.p.) & 2.5 & 0 \\
Pamitate & 0 & 0.25 \\
mp iont & 0.5 & 0 \\
High moisture corn & 0 & 3.8 \\
Brewer's grains & 6 & 10 \\
Wholecrop rye & 4 & 8 \\
Alfalfa haylage & 0 & 6 \\
Maize silage & 14 & 9
\end{tabular}

DOVP - complementary feed for lactating dairy cows; DOVP - a.p. - complementary feed for dairy cows ante partum

of these two indices. Vitamin A, E and beta carotene concentrations in serum were determined using the HPLC system Ultimate 3000 (Dionex, USA).

\section{Statistical analysis}

The obtained results were tested for homogeneity of variances (Hartley-Cochran-Bartlett test) and normality of distribution (Shapiro-Wilk test). The data were analysed statistically by one-way analysis of variance (ANOVA) followed by the Fisher's LSD post hoc test. All results were expressed as mean value $(\times) \pm$ standard deviation (SD).

\section{Results}

The mean GPx activity was significantly lower $(866.1 \mu \mathrm{kat} / \mathrm{l})$ in the fourth blood sampling (10-15 days p.p.) compared to the first $(15-20$ days a.p.; $P<0.05)$ and second (1-3 days a.p.; $P<0.01)$ blood samplings. A significant decrease $(747.9 \mu \mathrm{kat} / 1)$ in the GPx activity was also recorded 25-30 days p.p. compared to the blood collections before parturition $(P<0.001)$. Increased SOD values were recorded during the whole periparturient period. The lowest mean TAS concentration $(0.78 \mathrm{mmol} / \mathrm{l})$ was recorded in the third blood sampling (2-3 days p.p.) and was significantly lower $(P<0.01)$ compared to the fifth blood sampling (25-30 days p.p.). A significantly decreased TAS concentration $(0.84 \mathrm{mmol} / \mathrm{l})$ was also found at $10-15$ days p.p. compared to the TAS concentration at 25-30 days p.p. $(P<0.05)$. A significantly lower mean concentration of vitamin A $(0.48 \mu \mathrm{mol} / 1)$ was found in the third blood sampling (2-3 days p.p.) compared to the concentration in the first (15-20 days a.p.; $P<0.05)$, second ( $1-3$ days a.p.; $P<$ $0.01)$ and fifth $(25-30$ days p.p.; $P<0.001)$ blood samplings. A significant decrease in vitamin $E$ concentration $(4.10 \mu \mathrm{mol} / \mathrm{l})$ was also recorded in the cows at $2-3$ days p.p. compared to the cows at $15-20$ days a.p. $(P<0.001), 1-3$ days a.p. $(P<0.01)$ and $25-30$ days p.p. $(P<0.001)$. The lowest mean beta carotene concentration $(3.96 \mu \mathrm{mol} / \mathrm{l})$ was observed 2-3 days p.p. as with vitamins A and E (Table 2). 
Table 2. Antioxidant indices in dairy cows in the period from 15-20 days ante partum to 25-30 days post partum.

\begin{tabular}{|c|c|c|c|c|c|c|}
\hline Sampling no. & GPx $\mu$ kat/l & $\mathrm{SOD} \mathrm{U} / \mathrm{ml}$ & TAS mmol/l & vit $\mathrm{A} \mu \mathrm{mol} / \mathrm{l}$ & vit $\mathrm{E} \mu \mathrm{mol} / 1$ & $\beta-\mathrm{Car} \mu \mathrm{mol} / 1$ \\
\hline $\mathrm{x}$ & $1035.6^{\alpha, \mathrm{a}}$ & 331.2 & 0.87 & $0.76^{\alpha}$ & $8.06^{\mathrm{a}, \mathrm{a}}$ & 5.30 \\
\hline 15-20 days a.p. SD & 150.46 & 28.95 & 0.06 & 0.12 & 1.39 & 1.66 \\
\hline 2 & $1067.2^{\mathrm{A}, \mathrm{b}}$ & 348.8 & $0.81^{\mathrm{A}}$ & $0.79^{\mathrm{A}}$ & $7.29^{\mathrm{A}}$ & 4.87 \\
\hline 1-3 days a.p. & 115.33 & 26.16 & 0.10 & 0.17 & 1.38 & 1.16 \\
\hline $\mathrm{x}$ & $982.6^{\beta, c}$ & 368.5 & $0.78^{\mathrm{B}}$ & $0.48^{\alpha, \beta, \mathrm{A}, \mathrm{a}}$ & $4.10^{\mathrm{A}, \mathrm{a}, \mathrm{b}}$ & 3.96 \\
\hline 2-3 days p.p. & 147.18 & 80.00 & 0.12 & 0.13 & 2.08 & 1.35 \\
\hline 4 & $866.1^{\alpha, \beta, A}$ & 347.8 & $0.84^{\alpha}$ & $0.71^{\beta, \gamma}$ & $5.91^{\alpha}$ & 4.42 \\
\hline 10-15 days p.p. SD & 120.69 & 89.36 & 0.08 & 0.22 & 1.30 & 1.78 \\
\hline $\mathrm{x}$ & $747.9^{\mathrm{a}, \mathrm{b}, \mathrm{c}}$ & 371.5 & $0.95^{\alpha, \mathrm{A}, \mathrm{B}}$ & $0.93^{\gamma, \mathrm{a}}$ & $7.83^{b}$ & 4.36 \\
\hline 25-30 days p.p. SD & 85.10 & 42.11 & 0.09 & 0.29 & 3.24 & 2.09 \\
\hline
\end{tabular}

$\mathrm{x}$ - mean value; SD - standard deviation; significant differences between groups are indicated by using the same indices in a column: ${ }^{\alpha, \beta}-P<0.05 ;^{\mathrm{A}, \mathrm{B}}-P<0.01 ;{ }^{\mathrm{a}, \mathrm{b}, \mathrm{c}}-P<0.001$; a.p. - ante partum; p.p. - post partum; GPx - glutathione peroxidase; SOD - superoxide dismutase; TAS - total antioxidant status; vit A - vitamin A; vit $\mathrm{E}$ - vitamin $\mathrm{E} ; \beta$-Car - beta carotene

\section{Discussion}

The results demonstrate a decrease in antioxidant indices associated with the incidence of oxidative stress in the early postpartum period in dairy cows.

In the study, decreased GPx activity was recorded in all postpartum blood collections which is in accordance with our other study Píšt'ková et al. (2018) in which a significant difference in the GPx activity was recorded immediately after parturition and at 1 week p.p. Konvičná et al. (2015) also reported a decreased GPx activity at 1 week p.p. as a reason for increasing postpartum oxidative stress. The selenium-dependent antioxidant enzyme GPx, as one of the main components of the ADS, is extremely important in protecting the organism against ROS (Pilarczyk et al. 2012). In view of this fact, it is widely used in evaluating the antioxidant status. It is also used in the indirect determination of selenium status and indicates long-term selenium supplementation (Pavlata et al. 2000; Illek et al. 2017).

Another enzyme involved in the ADS is $\mathrm{Mn}, \mathrm{Cu}$ and $\mathrm{Zn}$-dependent SOD. These enzymes are considered the first line of defence against pro-oxidants (converting the superoxide to hydrogen peroxide) and are also among the main intracellular antioxidants (Bernabucci et al. 2005; Machado et al. 2014). In the present study, the highest level of SOD was found 25-30 days p.p. The value increased throughout the entire experiment, except for the fourth blood collection when a slight decrease was recorded. The trend for increasing SOD was also observed in the study by Konvičná et al. (2015). Gaál et al. (2006) also described SOD activity in cows, and found a significant increase of SOD activity at calving as compared to a control group (pre- and post-calving). Bernabucci et al. (2005) recorded the highest SOD activity at 4 days before calving with a subsequent decline to pre-natal values. As reported by Barja de Quiroga et al. (1992), the antioxidant system seems to be under homeostatic control. The increase in GPx and SOD activity before parturition could be the result of an effort to cope with the increasing amount of ROS (Bernabucci et al. 2005). However, the insufficient amount of antioxidants and continually increasing amount of ROS led to a decrease in the GPx activity. The increased SOD activity during the entire experiment was not significant and is probably not sufficient to prevent the occurrence of oxidative stress (Fig. 1).

The TAS concentration expresses the antioxidant capacity of the organism, provides information about the concentration of antioxidants in blood and provides information 


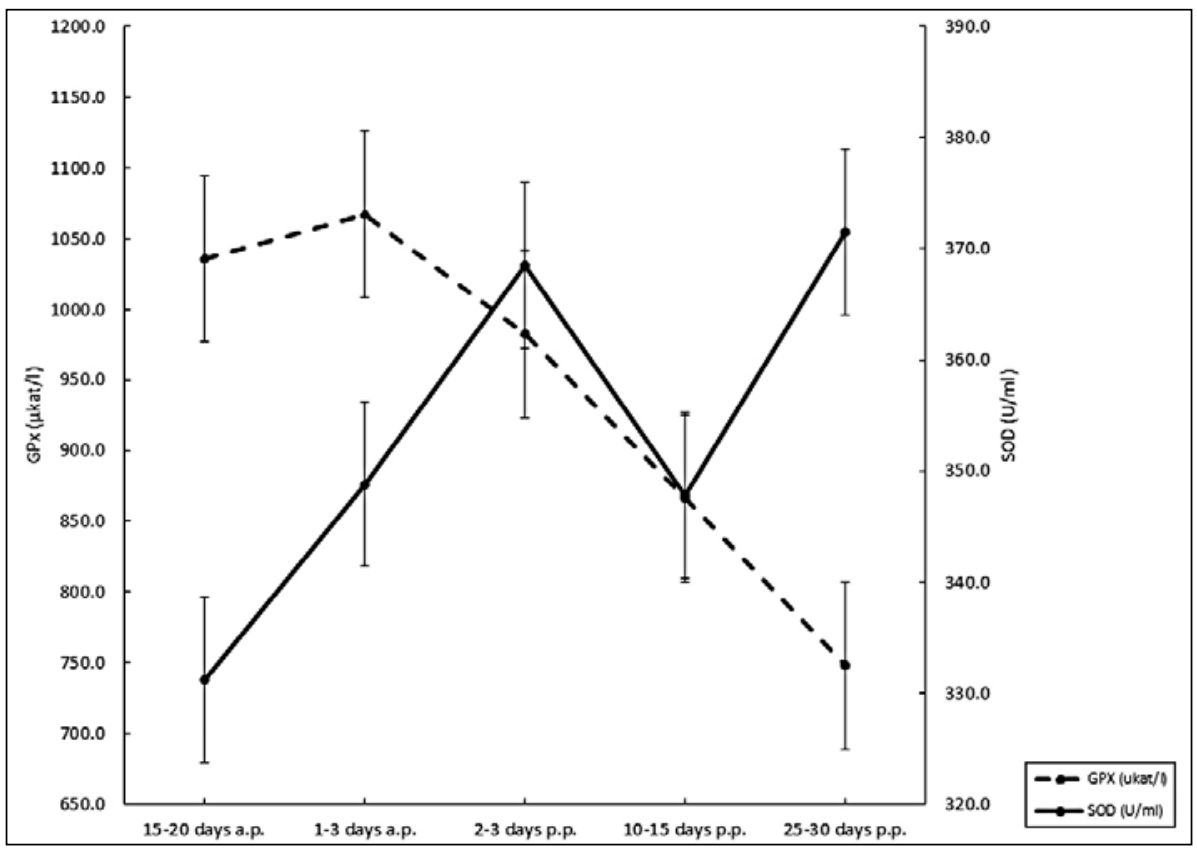

Fig. 1. Mean glutathione peroxidase (GPx) and superoxide dismutase (SOD) activities in dairy cows during the periparturient period

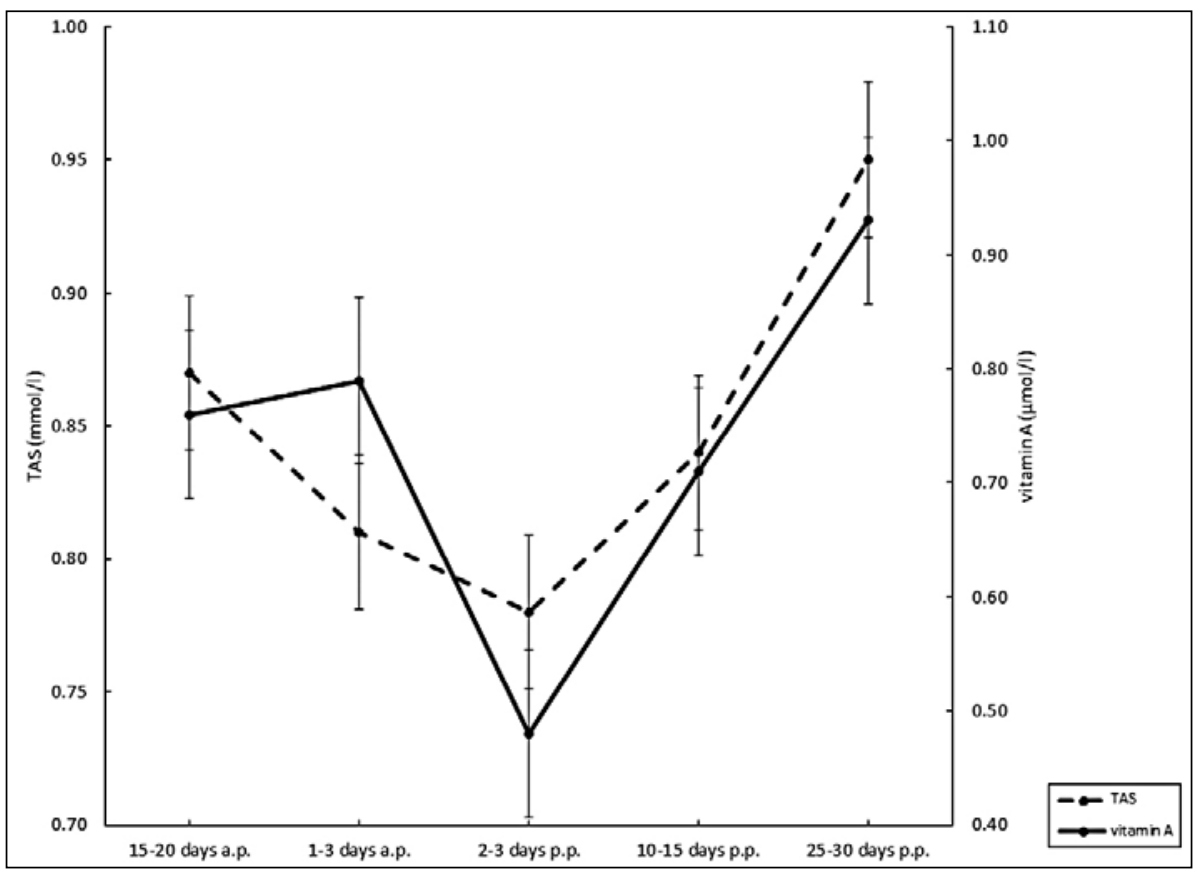

Fig. 2. Mean total antioxidant status (TAS) and vitamin A concentrations in dairy cows during the periparturient period 


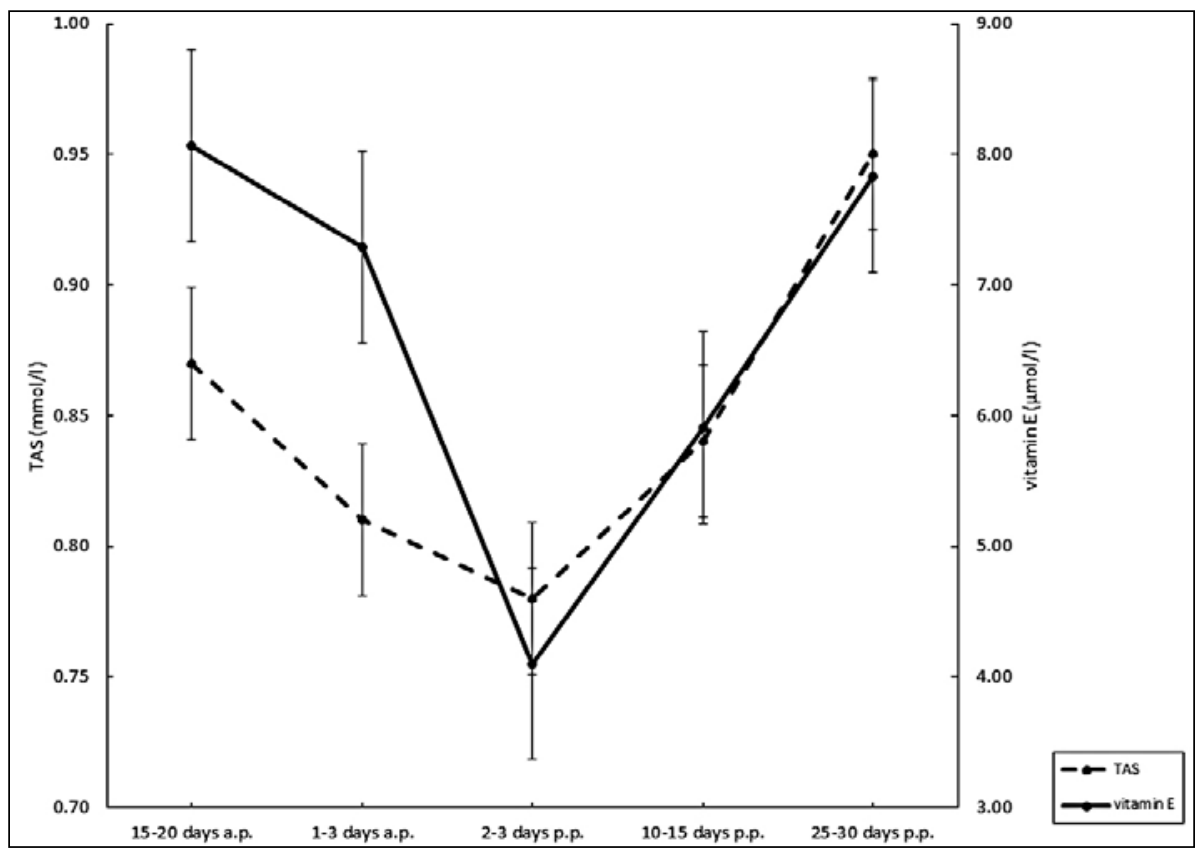

Fig. 3. Mean total antioxidant status (TAS) and vitamin E concentrations in dairy cows during the periparturient period

about the pro-oxidants to antioxidants balance (Ghiselli et al. 2000). In our study, the lowest TAS was found at 2-3 days p.p., as were the lowest vitamin A, E and beta-carotene concentrations which correspond to the total antioxidant capacity of the organism (Figs 2, $3)$. A decreased TAS level in the early lactation period was also found by Gong and Xiao (2016) and Píšt'ková et al. (2018).

Vitamins as non-enzymatic antioxidants are important free radical scavengers and are therefore an important part of the ADS (Sordillo and Aitken 2009). Their deficiency is typical for the periparturient period mainly because of their increase in the colostrum (Rizzo et al. 2013). In our study, a decrease in vitamin concentrations around parturition was also observed, as well as in the study by Píšt'ková et al. (2018) in which a significantly decreased vitamin A concentration was found immediately after parturition and the vitamin E concentration was significantly lower at 1 week p.p. This could be due to the forementioned release of vitamins from blood into the colostrum and an insufficient intake in the diet. Konvičná et al. (2015) recorded the lowest vitamin E value at 1 week p.p., followed by an increase in concentration until 9 week p.p. This is in agreement with our findings which also recorded an increase in all determined vitamins from 2-3 days p.p. until the last blood collection (25-30 days p.p.).

According to the study by Bernabucci et al. (2005), the cows in our experiment could be considered cows with a higher BCS (3.6 a.p.) which could be more sensitive to the occurrence of oxidative stress in the transition period. This fact may also contribute to explaining the decreased antioxidant concentrations in dairy cows after parturition.

There are several studies dealing with the relationship between oxidative stress and the incidence of periparturient diseases in dairy cows. One of the important predisposing factors for retained foetal membranes is the antioxidant status in dairy cows before parturition. According to the study by Pontes et al. (2015), supplementation with vitamin E during 
the prepartum period resulted in a reduced incidence of stillbirth and retained foetal membranes in dairy cows. The study by Kizil et al. (2010) focused on oxidative stress in dairy cows with acute puerperal metritis and determined plasma malondialdehyde (MDA) concentrations as a secondary product of lipid peroxidation. An increased mean MDA concentration and significantly decreased vitamin A, E, C and beta-carotene concentrations were found in cows with puerperal metritis compared to the control group. In addition to these diseases, dairy cows are also be prone to mastitis during the periparturient period. Production of ROS followed by oxidative stress, which may be one of the reasons for the disease, is increased because of the high energy demand caused by rapid differentiation of secretory parenchyma, intense mammary gland growth and onset of milk synthesis (Sordillo 2005). Oxidative stress can also contribute to bovine pneumonia in dairy cows. In some cases, neutrophils secrete reactive nitrogen intermediates (NO) in the lungs and alter acute or chronic inflammatory reactions. Tissue damage is caused by reaction with $\mathrm{O}_{2}^{--}$(Lykkesfeldt and Svendsen 2007).

In conclusion, our results confirm that the periparturient period is critical for the occurrence of oxidative stress, especially early post partum. Dairy cows are then more susceptible to the diseases listed above. Determination of antioxidant levels can be used to monitor the oxidative stress in order to prevent the incidence of the said diseases in dairy cows.

\section{Acknowledgement}

This study was supported by grant no. QJ1530058 from the Ministry of Agriculture of the Czech Republic.

\section{References}

Barja de Quiroga G, Lopez-Torres M, Perez-Campo R 1992: Relationship between antioxidants, lipid peroxidation and aging. EXS 62: 109-123

Bernabucci U, Ronchi B, Lacetera N, Nardone A 2005: Influence of body condition on relationships between metabolic status and oxidative stress in periparturient dairy cows. J Dairy Sci 88: 2017-2026

Esposito G, Irons PC, Webb EC, Chapwanya A 2014: Interactions between negative energy balance, metabolite diseases, uterine health and immune response in transitiv dairy cows. Anim Reprod Sci 144: 60-71

Gaál T, Ribiczeyné-Szabó P, Stadler K, Jakus J, Reiczigel J, Kövér Pál, Mézes M, Sümeghy L 2006: Free radicals, lipid peroxidation and the antioxidant system in the blood of cows and newborn calves around calving. Comp Biochem Physiol B Biochem Mol Biol 143: 391-396

Ghiselli A, Serafini M, Natella F, Scaccini C 2000: Total antioxidant capacity as a tool to assess redox status: critical view and experimental data. Free Radic Biol Med 29: 1106-1114

Gong J, Xiao M 2016: Selenium and antioxidant status in dairy cows at different stages of lactation. Biol Trace Elem Res 171: 89-93

Illek J 2017: Metabolic disorders in the periparturient period in cattle. Proceedings Book XVI International scientific and practical conference of professors, researchers, postgraduate students and students 'Actual questions in veterinary medicine', Proceedings Book, Kyiv, Ukraine, pp. 27-31

Illek J, Tulis F, Kudrna V, Kumprechtová D 2017: The selenium status of dairy herds in the Czech Republic. Hungarian Association for buiatrics, Proceedings Book XXVII, Nemzeközi Kongresszusa, pp. 28-31

Kizil O, Akar Y, Yuksel M, Saat N 2010: Oxidative stress in cows with acute puerperal metritis. Revue Med Vet 161: $353-357$

Konvičná J, Vargová M, Paulíková I, Kováč G, Kostecká Z 2015: Oxidative stress and antioxidant status in dairy cows during prepartal and postpartal periods. Acta Vet 84: 133-140

Lykkesfeldt J, Svendsen O 2007: Oxidants and antioxidants in disease: Oxidative stress in farm animals. Vet J 173: 502-511

Machado VS, Oikonomou G, Lima SF, Bicalho MLS, Kacar C, Foditsch C, Felippe MJ, Gilbert RO, Bicalho RC 2014: The effect of injectable trace minerals (selenium, copper, zinc, and manganese) on peripheral blood leukocyte activity and serum superoxide dismutase activity of lactating Holstein cows. Vet J 200: 299-304

Miller JK, Slebodzinska-Brzezinska E, Madsen FC 1993: Oxidative stress, antioxidants, and animal function. J Dairy Sci 76: 2812-2823

Paglia DE, Valentine WN 1967: Studies on the quantitative and qualitative characterization of erythrocyte glutathione peroxidase. J Lab Clin Med 70: 158-169

Pavlata L, Pechová A, Illek J 2000: Direct and indirect assessment of selenium status in cattle - a comparison. Acta Vet 69: 281-287

Pilarczyk B, Jankowiak D, Tomza-Marciniak A, Pilarczyk R, Sablik P, Drozd R, Tylkowska A, Skolmowska M 2012: Selenium concentration and glutathione peroxidase (GSH-Px) activity in serum of cows at different stages of lactation. Biol Trace Elem Res 147: 91-96 
Píšt'ková K, Kazatelová Z, Procházková H, Danielová L, Illek J 2018: Antioxidant status and concentration levels of malondialdehyde (MDA) in dairy cows during periparturient period. Magy Allatorvosok, Proceedings, XVIII. Middle-European Biuatrics Congress 140 (Supplement I): 312-319

Pontes GCS, Monteiro Jr. PLJ, Prata AB, Guardieiro MM, Pinto DAM, Fernandes GO, Wiltbank MC, Santos JEP, Sartori R 2015: Effect of injectable vitamin E on incidence of retained fetal membranes and reproductive performance of dairy cows. J Dairy Sci 98: 2437-2449

Rizzo A, Pantaleo M, Mutinati M, Minoia G, Trisolini C, Ceci E, Sciorsci RL 2013: Blood and milk oxidative status after administration of different antioxidants during early postpartum in dairy cows. Res Vet Sci 95: 1171-1174

Sordillo LM 2005: Factors affecting mammary gland immunity and mastitis susceptibility. Livest Prod Sci 98 : 89-99

Sordillo LM, Aitken SL 2009: Impact of oxidative stress on the health and immune function of dairy cattle. Vet Immunol Immunopathol 128: 104-109

Spears JW, Weiss WP 2008: Role of antioxidant and trace elements in health and immunity of dairy cows. Vet J 176: $70-76$ 